Int. J. Electrochem. Sci., 14 (2019) 9726 - 9740

\title{
Corrosion Inhibition Effect of Sodium Pyrophosphate on Carbon Steel in Chloride Contaminated Mortar
}

\author{
Yiwen Xu ${ }^{1}$, Chao Zhu ${ }^{1}$, Shengli Chen ${ }^{3}$, Yiji Zhang ${ }^{1}$, Tong Wu ${ }^{1}$, Xiangyu Lu ${ }^{1,2, *}$, Mai Wang ${ }^{4}$, \\ Xingguo Feng ${ }^{1,2}$ \\ ${ }^{1}$ Jiangsu Key Laboratory of Coast Ocean Resources Development and Environment Security, Hohai \\ University, Nanjing 210098, Jiangsu, China \\ ${ }^{2}$ State Key Laboratory of Geohazard Prevention and Geoenvironment Protection, Chengdu University \\ of Technology, Chendu 610059, Sichuan, China \\ ${ }^{3}$ CNOOC information technology Co., Ltd. Oceanographic information Center, Beijing 100013, China \\ ${ }^{4}$ Air Force Command College, Beijing 100089, China \\ *E-mail: luxiangyu@hhu.edu.cn
}

doi: $10.20964 / 2019.10 .25$

Received: 5 June 2019 / Accepted: 4 August 2019 / Published: 30 August 2019

\begin{abstract}
Reinforced concrete structures suffered severe degradation for the corrosion of the steel bar, and the utilization of phosphate corrosion inhibitors was an eco-friendly as well as an effective method to reduce the steel corrosion. Sodium pyrophosphate (SPP) was used to inhibit the corrosion of the steel bar in the chloride contaminated mortar. The corrosion behavior of the rebar in mortars containing different concentrations of SPP was investigated via electrochemical tests. The results showed that the SPP can efficiently hinder the corrosion of the rebar in the chloride-containing mortars. In the samples containing SPP with a concentration of $0.6 \%$ by the weight of cement, the corrosion of rebar was most effectively inhibited. The excessive addition of SPP could cause the degradation of mortar cover layer and reduce its inhibition efficiency.
\end{abstract}

Keywords: corrosion inhibitor; sodium pyrophosphate; mortar; carbon steel; electrochemical tests

\section{FULL TEXT}

(C) 2019 The Authors. Published by ESG (www.electrochemsci.org). This article is an open access article distributed under the terms and conditions of the Creative Commons Attribution license (http://creativecommons.org/licenses/by/4.0/). 